\title{
Decreased Expression of TRPM3 and mAChRM3 in the Small Intestine in Chronic Fatigue Syndrome/Myalgic Encephalomyelitis
}

\author{
Sonya Marshall-Gradisnik ${ }^{1,2^{*}}$, Marshall Fretel ${ }^{1,2}$, Natalie Eaton ${ }^{1,2}$, Helene Cabanas ${ }^{1,2}$, \\ Cassandra Balinass,2, Vinod Gopalan1, Daniel Petersen'2, Rachel Passmore ${ }^{1,2}$, \\ Kevin Tang2,3, Mazhar Haque ${ }^{4}$, Alfred Lam¹, Donald Staines ${ }^{1,2}$ \\ ${ }^{1}$ School of Medical Science, Griffith University, Brisbane, Australia \\ ${ }^{2}$ The National Centre for Neuroimmunology and Emerging Diseases, Menzies Health Institute Queensland, Griffith University, \\ Brisbane, Australia \\ ${ }^{3}$ Gold Coast University Hospital, Parklands, Australia \\ ${ }^{4}$ Mater Hill Gastroenterology, South Brisbane, Australia \\ Email: *ncned@griffith.edu.au
}

How to cite this paper: Marshall-Gradisnik, S., Fretel, M., Eaton, N., Cabanas, H., Balinas, C., Gopalan, V., Petersen, D., Passmore, R., Tang, K., Haque, M., Lam, A. and Staines, D. (2018) Decreased Expression of TRPM3 and mAChRM3 in the Small Intestine in Chronic Fatigue Syndrome/Myalgic Encephalomyelitis. International Journal of Clinical Medicine, 9, 467-480.

https://doi.org/10.4236/ijcm.2018.95040

Received: May 8, 2018

Accepted: May 28, 2018

Published: May 31, 2018

Copyright $\odot 2018$ by authors and Scientific Research Publishing Inc. This work is licensed under the Creative Commons Attribution International License (CC BY 4.0).

http://creativecommons.org/licenses/by/4.0/

\begin{abstract}
Introduction: Chronic Fatigue Syndrome/Myalgic Encephalomyelitis (CFS/ME) is often associated with gastrointestinal disturbance and inflammatory markers; however, there have been no histological studies performed in the small intestine from CFS/ME patients. The aim of this investigation was to assess the expression of certain inflammatory markers and inflammatory receptors, namely transient receptor potential melastin 3 (TRPM3) ion channels and muscarinic acetylcholine M3 (mAChRM3) receptors, in small intestinal tissues in a case controlled study comprising a CFS/ME patient and a healthy non-fatigued control. Method: Immunohistochemistry was performed on a small intestinal biopsy from a CFS/ME patient (age $=50$; female) with self-reported symptoms of gastrointestinal disturbance and a non-fatigued control $(\mathrm{NFC})$, (age $=28$; female). Semi-quantitative analysis of expression was undertaken for interferon-gamma (IFNy), interleukin-1 alpha (IL-1 $\alpha$ ), tumour necrosis factor-alpha (TNF $\alpha$ ), TRPM3 ion channels and mAChRM3 acetylcholine receptors. Results: There was significantly decreased expression of TRPM3 in the CFS/ME patient $(35 \% \pm 9 \%)$ and a significant decrease in mAChRM3 in the CFS/ME patient $(54 \% \pm 9 \%)$. There was no difference in IL- $1 \alpha$ between CFS/ME patient and NFC, however; there was an increase in IFNy $(13 \% \pm 6 \%)$ in the CFS/ME patient compared to NFC. There was a difference observed in TNF $\alpha$ in CFS/ME compared to NFC. Conclusion: Differences were noted in the expression of specific TRP ion channels and cholinergic receptors in CFS/ME compared with NFC, with CFS/ME demon-
\end{abstract}


strating decreased TRPM3 and mAChRM3. Further, IFNy was increased, and $\mathrm{TNF} \alpha$ decreased, in the small intestine of the CFS/ME patient with reported gastrointestinal disturbance.

\section{Keywords}

Chronic Fatigue Syndrome/Myalgic Encephalomyelitis, Irritable Bowel, TRPM3, mAChRM3, Small Intestine, Inflammation

\section{Introduction}

Chronic Fatigue Syndrome/Myalgic Encephalomyelitis (CFS/ME) is a complex and unexplained disorder associated with several physiological systems including the gastrointestinal (GI) tract [1] [2]. The prevalence of CFS/ME globally is uncertain, however, estimates range from $0.2 \%$ to $1.3 \%$ in primary health care [3]. In the absence of a biological marker, diagnosis is based on symptom criteria and differentiating symptoms from other conditions. Many CFS/ME patients experience GI disturbances that are hallmarks of irritable bowel syndrome (IBS) including abdominal pain and alterations in bowel habit [4] [5] [6] [7]. The pathomechanisms of GI disturbances in CFS/ME are unknown, although evidence suggests mediation by increased intestinal permeability, microbiota imbalance and persistent inflammation [1] [8] [9] [10].

Reports indicate chronic inflammation in CFS/ME is characterised by immunological dysfunction. Multiple studies describe elevated systemic levels of pro-inflammatory cytokines while others, at times in the same cohort, have observed increases in anti-inflammatory cytokines [1] [11]-[17]. The incongruence in results across studies is likely a consequence of the heterogeneous nature of $\mathrm{CFS} / \mathrm{ME}$ but also an abnormal immune signature. In a network analysis of cytokine co-expression in CFS/ME, inflammatory profiles suggest an overriding Th2 response [18]. The contribution of disrupted cytokine production to GI pathology in CFS/ME is uncertain although studies indicate elevated systemic inflammation is a by-product of spill-over from foci in the gut, a possible result of microbiome dysbiosis and bacterial translocation [19] [20] [21] [22]. Evidence of impaired mucosal integrity via serum levels of IgA and IgM to enterobacteria may account for inflammation and viscseral hypersensitivity in CFS/ME [21].

Transient receptor potential (TRP) ion channels are ubiquitously expressed in most tissues and physiological function depends on the location of expression. TRPs are non-selective cation permeable channels and are involved in intracellular $\mathrm{Ca}^{2+}$ signalling [23]. Channelopathies associated with TRP function lead to disorders/diseases including chronic pain, overactive bladder and neurosensory/motor neuropathies that parallel clinical presentation of CFS/ME [23]. TRPs are comprised of six main groups in humans: TRPA (ankyrin), TRPC (canonical), TRPM (melastatin), TRPML (mucolipin), TRPP (polycystin) and TRPV (vanilloid) [24]. Of the TRP channels, TRPM3 encodes the largest num- 
ber of variants through alternative splicing events [25]. We have detected genetic anomalies in the TRPM3 gene in peripheral lymphocytes in CFS/ME [26]. Additionally, we have reported significant reduction in the expression of TRPM3 on Natural Killer cells and significant reduction in calcium stores and entry following stimulation of TRPM3 on NK cells [27] [28], which may contribute to altered $\mathrm{Ca}^{2+}$ metabolism and function [26] [27]. However, due to the difficulty of obtaining biological tissue samples from patients, there has been little avenue to assess the expression of TRPM3 on tissue other than blood cells.

Cellular distribution of nicotinic acetylcholine receptors (nAChR) and muscarinic acetylcholine receptors ( $\mathrm{mAChR}$ ) is diverse with expression in the central-, peripheral-, and autonomic nervous systems. Additionally, mAChRs are present in immune cells and tissues of the GI tract. Acetylcholine receptors (AChR), particularly mAChR M1, can inhibit TRPM3 via phospholipase C activity and potentially play a vital role in GI pathology [29] [30]. Mutations in $\mathrm{mAChR}$ genes may result in altered function of these receptors and we have identified single nucleotide polymorphisms (SNP) in $\mathrm{mAChR}$ genes in CFS/ME [30]. The functional implications of $\mathrm{mAChR}$ SNPs and the association with TRPM3 are still unknown [30].

To our knowledge, there are no histological studies that determine inflammation, TRPM3 ion channel and mAChR expression as well as inflammatory markers in small intestinal tissues in CFS/ME. The aim of this pilot study is to compare histological markers of inflammation and expression of TRPM3 and mAChRM3 in a CFS/ME patient compared to a non-fatigued control.

\section{Methods}

\subsection{Participants}

Clinical diagnosis of CFS/ME follows the Fukuda criteria which include unexplained fatigue often accompanied by cognitive impairment, unrefreshed sleep, headaches, myalgia, arthralgia and other flu-like symptoms [31]. Alternative diagnostic algorithms are used, i.e. the International Consensus Criteria (ICC) which comprises a range and severity of symptoms associated with neurological, immunological, autonomic and GI imbalances observed in the disorder [2]. One CFS/ME patient and one non-fatigued control (NFC) were recruited for this study. The CFS/ME patient completed a comprehensive questionnaire corresponding with the Fukuda and ICC criteria. The CFS/ME patient was clinically diagnosed as severe CFS/ME and met both Fukuda and ICC requirements. Clinical characteristics are summarised in Table 1. Participants were excluded from this study if they reported history of smoking, autoimmune diseases, cardiac disease, diabetes or other co-morbidities in addition to pregnancy or breast-feeding. A self-report survey regarding symptom frequency and severity is summarised in Table 2.

CFS/ME Patient. 50-year old female, $168 \mathrm{~cm}$ and $70 \mathrm{~kg}$. Patient experienced mild symptoms of CFS/ME during childhood although clinical diagnosis not 
Table 1. Sociodemographic and clinical characteristics.

\begin{tabular}{|c|c|c|}
\hline & $\mathrm{CFS} / \mathrm{ME}(\mathrm{n}=1)$ & $\operatorname{NFC}(\mathrm{n}=1)$ \\
\hline \multicolumn{3}{|l|}{ Sociodemographic } \\
\hline Age (years) & 50 & 28 \\
\hline Gender & Female & Female \\
\hline \multicolumn{3}{|l|}{ Clinical } \\
\hline PENE & Yes & None \\
\hline Cognitive Impairments & Yes & None \\
\hline Neurosensory Disturbances & Yes & None \\
\hline Body Pain & Yes & None \\
\hline Headaches & Yes & None \\
\hline Abdominal Pain & Yes & None \\
\hline Gastrointestinal sensitivites & Yes & None \\
\hline Genituourinary Disturbances & Yes & None \\
\hline Nausea & Yes & None \\
\hline Bloating & Yes & None \\
\hline Food/medication/chemical insensitivities & Yes & None \\
\hline Flu-like symptoms & Yes & None \\
\hline Thermostatic Instability & Yes & None \\
\hline Cardiovascular and Respiratory disturbances & Yes & None \\
\hline
\end{tabular}

Clinical characteristics outlined correspond with the CFS/ME inclusion questionnaire. Abbreviations. CFS/ME, chronic fatigue syndromelmyalgic encephalomyelitis: NFC, non-fatigued control: PENE, post-exertional neuroimmune exhaustion.

Table 2. Self-reported frequency and severity of symptoms of CFS/ME patient.

\begin{tabular}{clc}
\hline \multirow{2}{*}{ Symptom } & \multicolumn{2}{c}{ CFS/ME patient } \\
\cline { 2 - 3 } Pain & Frequency & Severity \\
\hline Difficulty Processing Information & Often & 7 \\
Sleep Disturbances & Often & 7 \\
Sensory Disturbances & Often & 8 \\
Flu-like/immune symptoms & Often & 8 \\
Bowel and urinary & Often & 7 \\
Cardiovascular & Often & 7 \\
Respiratory & Often & 8 \\
Thermostatic instability & Often & 8 \\
\hline
\end{tabular}

Frequency ranking = never, rarely, often, quite often. Severity ranking $=1-10 ; 1=$ very good, $10=$ poor. 
made until age 39. The patient had a history of orthostatic intolerance and was on a disability pension. Self-reported symptoms include GI sensitivities and genitourinary disturbances: severe abdominal pain, nausea, bloating,

food/medication/chemical insensitivities and urinary frequency and nocturia. Patient nutritional intake followed a Western Dietary pattern [32]. Medications include Movicol, melatonin, acetyl L-Carnitine, CoQ10, alpha-lipoic acid, vitamin D3, magnesium $\left(\mathrm{Mg}^{2+}\right)$, acidophilus, B complex, multivitamin, vitamin A and fish oil. All medications were ceased $48 \mathrm{~h}$ prior to biopsy.

$N F C$ : The NFC participant was female (age $=28$ ) with no history of CFS/ME or immune dysfunction or inflammatory disorder, not pregnant or breast feeding and not clinically diagnosed with IBS or any gastrointestinal disorder.

All participants were residents of Australia at the time of the study. The project was approved under the Human Ethics Research Committee Griffith University (MSC/05/HREC).

\subsection{Patient Samples}

$10 \%$ formalin fixed, paraffin embedded small intestinal biopsy samples were collected from NFC and CFS/ME participants at Mater Private Hospital in Brisbane and Pacific Private Hospital in Southport, QLD. Frozen tissue sections were cut $(4 \mu \mathrm{m})$ using a Leica microtome (Leica RM2235, Wetzler, Germany) and placed on tissue adhesive microscope slides (Lamb Scientific, NSW, Australia).

\subsection{Immunohistochemistry}

In brief, slides were deparaffinised and dried with graded dilutions of xylene and alcohol. Antigen retrieval was performed in TE Buffer (Gibco, Thermofisher Scientific, Australia) at $150 \mathrm{~W}$ for $20 \mathrm{~min}$. Endogenous peroxidase was blocked for $5 \mathrm{~min}$ followed by a protein block for $5 \mathrm{~min}$. Tissue sections were stained using the Novolink Polymer Detection System (Leica, Wetzler, Germany) according to manufacturer instructions. Slides were incubated with polyclonal antibodies against hTRPM3 (H-300, 1/600 dilution: Santa Cruz Biotechnology Inc, USA), hmAChRM3 (H-210, 1/700 dilution: Santa Cruz Biotechnology Inc, USA), and monoclonal antibodies against IL-1 $\alpha$ (5G3, 1/50 dilution: Santa Cruz Biotechnology Inc, USA), IFN- $\gamma$ (LLO6Z, 1/50 dilution: Santa Cruz Biotechnology Inc, USA) and TNF $\alpha$ (52B83, 1/700 dilution: Santa Cruz Biotechnology Inc, USA). Antibodies were detected using the Novolink polymer reagent (anti-mouse/anti-rabbit IgG-poly-HRP) for $20 \mathrm{~min}$ followed by visualisation with $\mathrm{DAB}$ (3, 3'-diaminobenzidine) solution. Slides were counterstained with haematoxylin followed by Scott's Blueing solution.

\subsection{Image Analysis}

Image analysis was performed using Apeiro software (Leica Biosystems, Wetzler, Germany). As a negative control, distilled $\mathrm{H}_{2} \mathrm{O}$ was substituted for primary antibody. Slides were examined $(40 \times)$ in 5 random fields and 100 lymphocytes 
counted per field. Immunochemical staining was assessed semi-quantitatively in 4 categories: 0 to less than $5 \%$ positive (0), $5 \%$ to $30 \%$ of cells positive $(1+), 31 \%$ to $60 \%$ of cells positive $(2+)$, and $61 \%$ to $100 \%$ of cells positive $(3+)$. Protein expression were labelled as "high" when protein expression was $2+/ 3+$, whereas categories $0,1+$ were labelled as "low".

\section{Results}

\subsection{TRPM3 and mAChRM3}

There was a significant reduction observed in TRPM3 in mucosal lymphocytes in the CFS/ME patient (0\%) compared with the NFC $(35 \% \pm 9 \%)$. There was a significant decrease in mAChRM3 in the CFS/ME patient (0\%) compared with NFC $(54 \% \pm 9 \%)$. IHC images are provided in Figure 1.

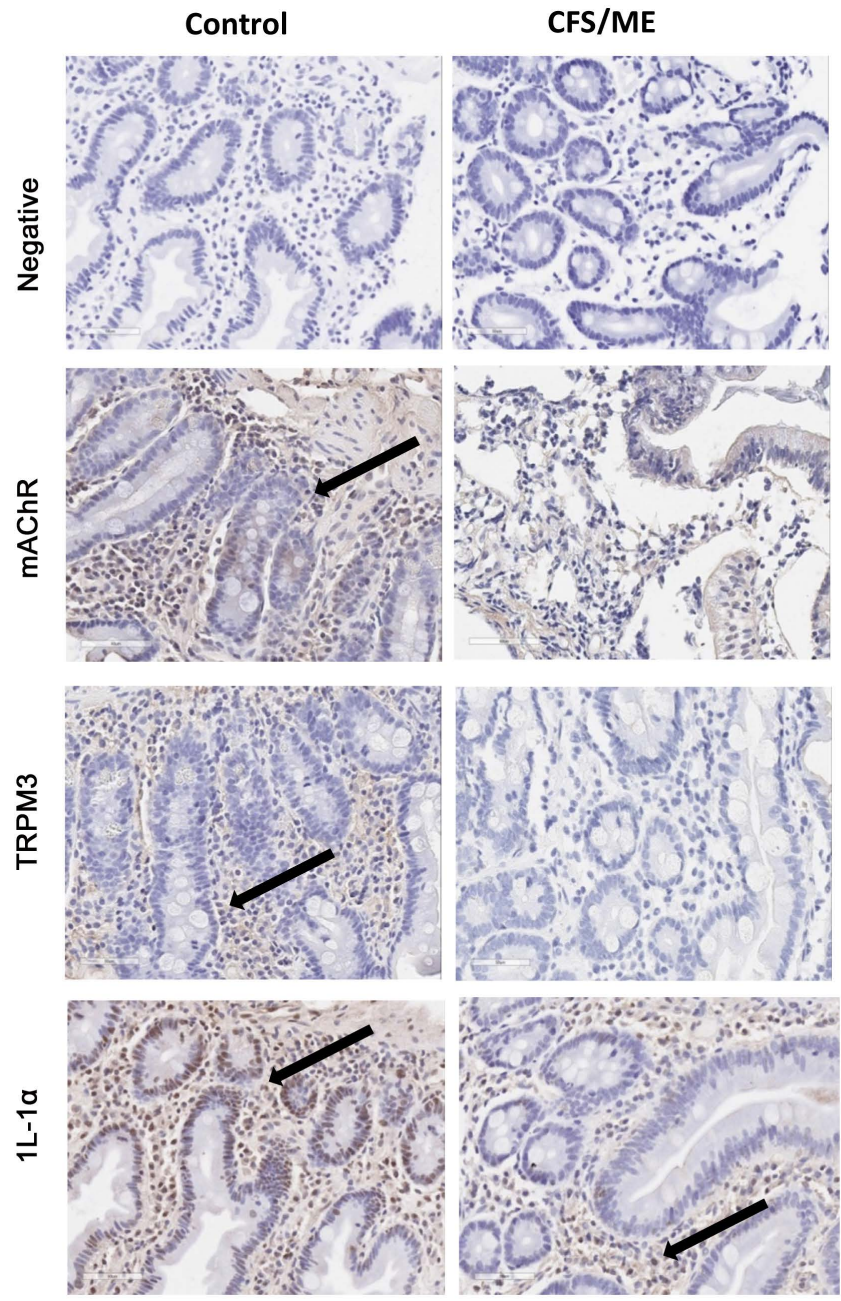

Figure 1. Immunohistochemistry staining of protein expression for $\mathrm{mAChRM} 3$ and TRPM3 in muscosal lymphocytes in CFS/ME small intestine. Results for negative control staining provided in row 1, mAChRM3 (row 2), TRPM3 (row 3), IL- $1 \alpha$ (row 4), IFN $\gamma$ (row5) and TNF $\alpha$ (row 6). Results for non-fatigued control (column 1) and CFS/ME patient (column 2). Positive staining indicated by a brown precipitate in cells. Black arrows are provided to identify an example of a positive cell. All images (40×). 


\subsection{Inflammatory Markers}

There was no difference between the CFS/ME patient $(75 \% \pm 13 \%)$ and NFC for IL-1 $\alpha(69 \% \pm 10 \%)$. In contrast, there was a significant increase in IFNy $(13 \% \pm$ $6 \%)$ in the CFS/ME patient compared to NFC (0\%). There was a significant difference in TNF $\alpha$ between the CFS/ME patient ( $0 \%)$ and NFC (53\% $\pm 20 \%)$. Results of IHC expression are summarised in Table 3. IHC images are provided in Figure 1.

\section{Discussions}

This is the first histological case study examining pro-inflammatory cytokines, TRPM3 and mAChRM3 receptors in the small intestine of a CFS/ME patient. Overall, we observed a decrease in cytokines, TRPM3 and mAChRM3 expression in the CFS/ME patient mucosal lymphocytes compared with NFC and may justify future investigations into mucosal immune cell function and GI pathology in this illness.

Our investigation found a reduction in TRPM3 mucosal lymphocytes in the CFS/ME patient compared to NFC and supports our previous findings where TRPM3 surface expression on CD56 $6^{\text {bright }}$ NK cells and B lymphocytes was significantly reduced in CFS/ME patients compared to controls [27] [28]. In conjunction with significant reduction in TRPM3 expression on immune cells, we also reported a significant decrease in intracellular $\mathrm{Ca}^{2+}$ following stimulation of the TRPM3 receptor by the its natural ligand, pregnenolone sulfate, as well as significantly lower intracellular $\mathrm{Ca}^{2+}$ stores from NK cells from CFS/ME patients. Collectively, these studies indicate the TRPM3 receptor may be dysfunctional,

Table 3. Immunohistochemistry examination of TRPM3, mAChRM3 and cytokine expression in small intestine of CFS/ME compared to NFC.

\begin{tabular}{|c|c|c|c|c|}
\hline Protein & $\begin{array}{c}\text { High } \\
\text { Expression } \\
(2+/ 3+)\end{array}$ & $\begin{array}{c}\text { Low } \\
\text { Expression } \\
(0,1+)\end{array}$ & $\begin{array}{c}\text { Expression } \\
\text { compared } \\
\text { to NFC }\end{array}$ & $P$ value \\
\hline \multicolumn{5}{|l|}{ TRPM3 } \\
\hline CFS/ME Patient & & $0(100 \%)$ & $\downarrow$ & $0.001 \mathrm{a}$ \\
\hline Control & $2+(35 \%)$ & & & \\
\hline \multicolumn{5}{|l|}{ mAChRM3 } \\
\hline CFS/ME Patient & & $0(100 \%)$ & $\downarrow$ & $0.001 \mathrm{a}$ \\
\hline Control & $2+(54 \%)$ & & & \\
\hline \multicolumn{5}{|l|}{ IL- $\alpha$} \\
\hline CFS/ME Patient & $3+(69 \%)$ & & $\mathrm{Nd}$ & 0.599 \\
\hline Control & $3+(75 \%)$ & & & \\
\hline \multicolumn{5}{|l|}{$\operatorname{IFN} \gamma$} \\
\hline CFS/ME Patient & & $1+(13 \%)$ & $\uparrow$ & $0.040 \mathrm{a}$ \\
\hline Control & & $0(100 \%)$ & & \\
\hline \multicolumn{5}{|l|}{ TNF $\alpha$} \\
\hline CFS/ME Patient & & $0(100 \%)$ & $\downarrow$ & $0.011 \mathrm{a}$ \\
\hline Control & $2+(53 \%)$ & & & \\
\hline
\end{tabular}

a Significant at $\alpha=0.05 ; \mathrm{ND}=$ No Difference, NFC $=$ non-fatigued control. 
resulting in dysregulation of calcium mobilisation. Importantly, this current investigation supports these findings, suggesting disturbed cell signalling mechanisms are common in CFS/ME [33] [34]. Moreover, functional studies of TRPM3 variants have also indicated the absence of specific residues that disable $\mathrm{Ca}^{2+}$ entry and mobilisation into cells in rodent and human tissue. Furthermore, $\mathrm{Ca}^{2+}$ entry in cells co-expressing TRPM3 variants and wild type TRPM3 channels has been reported to be diminished [35]. TRPM3 is involved in thermal and nociceptive sensation and abnormal responses to heat have been identified in TRPM3 knockout mice [25]. Interestingly, CFS patients report changes in thermoregulation [2] [36] [37].

In this study, we were the first to focus on TRPM3 due to our previous research reporting genetic and proteomic changes of TRPM3 in CFS/ME. The results from this research may provide evidence for the role of TRPM3 in the pathomechanism in CFS/ME. Additionally, the role of TRP receptors in the possible development of the pathomechanisms of CFS/ME may be highlighted through TRPV1 and TRPV4 mediated thermal, chemical, nociceptive and mechanosensation responses in the alimentary canal [38]. TRPV1 is prominently expressed in visceral afferent neurons in the GI tract and may mediate immune responses observed in inflammatory thermal hyperalgesia in the GI mucosa [39]. An increase in TRPV1 immunoreactivity in colonic nerve fibres of IBS patients with hypersensitivity/hyperalgesia has been reported in addition to studies demonstrating upregulation of TRPV1 in leukocytes of CFS/ME [40] [41]. Similarly, TRPV4 is expressed throughout the GI tract, primarily in sensory neurons of the colon [42] [43]. In rodent models of colitis and in human colonic tissue from patients with IBS, TRPV4 is upregulated in epithelial cells and lymphocyte infiltrates [44]. Additionally, increased mast cell and CD3+ lymphocytes are found in the lamina propria in close proximity to enteric nerve fibres [19] [43]. Studies indicate that mast cell regulators (histamine and tryptase) can exacerbate nociceptive responses in IBS via afferent enteric neurons [43]. Interestingly, we have identified abnormalities in mast cell function in CFS/ME that may contribute to GI dysfunction as histamine and tryptase are agonists of TRPV4 [28]. Although the current investigation only reports significant changes in TRPM3, further examination of TRPV1 and TRPV4 is warranted.

We observed significantly less mAChRM3 expression in the mucosal lymphocytes in the CFS/ME patient compared with the non-fatigued control. Interestingly, one of the SNP intron variants (rs7520974) we identified previously is associated with gastric smooth muscle contraction [30] [45]. While a paucity of information exists on the interactions between mAChRM3 and TRP ion channels, further investigations are needed given recent studies have outlined the antagonistic effect of phospholipase C coupled mAChR M1 receptor on TRPM3 in HEK-M3 cells [46] [47].

In this present investigation, we observed no difference in IL- $1 \alpha$ expression in the CFS/ME patient compared to NFC. While lymphocyte phenotype populations were not investigated in our study, a precedent of altered CD8+ T cell, and 
particularly NK cell function in CFS/ME exists [48] [49]. Certain NK cell subsets in CFS/ME exhibit altered cytokine production [48]. In the periphery, CD56 ${ }^{\text {bright }}$ NK cells produce IFN $\gamma$, TNF $\beta$, IL-13 and IL-10 during innate immune responses [50]. In a longitudinal analysis of NK cell phenotypes in CFS/ME we found a decrease in $\mathrm{CD}^{\text {bright }}{ }^{\mathrm{CD}} 16-\mathrm{NK}$ cells over time. In this same study IFN $\gamma, \operatorname{TNF} \alpha$ and IL-10 expression were significantly increased [13] [48]. In a retrospective network analysis of cytokines in CFS/ME, Broderick et al. described the presence of a tight knit cluster of association and interaction between cytokines IL- $1 \beta$, IL-4, IFN $\gamma$ and TNF $\alpha$. Median IL-4 concentrations in this study were increased 3 -fold in CFS/ME groups while IL-2, IFN $\gamma$ and TNF $\alpha$ concentrations remained unchanged. This finding supports the presence of an active Th2 profile and an antagonistic role of IL- 4 towards Th 1 cytokines IFN $\gamma$ and TNF $\alpha$ [18]. While we did not examine IL-4, the aforementioned findings may explain the low level expression of IFN $\gamma$ in our investigation via Th2 cytokine antagonism. We have described the expression of other inflammatory cytokines in previous studies [48] and further examination of an expanded cytokine array in small intestinal tissues of CFS/ME is warranted.

There was no expression of TNF $\alpha$ in the CFS/ME patient. In contrast, the NFC exhibited high levels of TNF $\alpha$ expression. In CFS/ME and IBS, elevated systemic levels of TNF $\alpha$ are common [34] [51]. In the current study, the high degree of complementary alternative medicines (CAMs) taken by the patient may have contributed to the reduction in inflammation, particularly TNF $\alpha$ [52].

This is the first assessment of small intestinal biopsy sample from a CFS/ME patient, as acquisition of samples is a particular challenge and is not routinely collected in this illness. Hence, the current study represents a specific case of $\mathrm{CFS} / \mathrm{ME}$ and future directions would aim to assess these findings in a larger case-control study design. While we observed a reduction in a small subset of inflammatory markers, further studies using a larger array of cytokines will further elucidate the immunological signature of CFS/ME. The findings in this pilot study warrant future investigation into TRPV1, TRPV4, TRPM3 and mAChR expression in the small intestine in CFS/ME.

\section{Acknowledgements}

The authors would like to acknowledge the contribution of the Gold Coast Health and Medical Research Foundation, Stafford Fox Medical Research Foundation, Mr Douglas Stutt, Alison Hunter Memorial Foundation and Charity for Change for M.E.

\section{List of Abbreviations}

AChR, acetylcholine receptors; mAChRM3, acetylcholine muscarinic receptor M3; CFS/ME, chronic fatigue/myalgic encephalomyelitis; GI, gastrointestinal tract (GI); IL- $1 \alpha$ interleukin 1 alpha; IFN $\gamma$, interferon gamma; IBS, irritable bowel syndrome ; NFC, non-fatigued control; TRPV1, transient receptor poten- 
tial vanilloid receptor 1; TRPV4, transient receptor potential vanilloid receptor 4; TRPM3, transient receptor potential melastatin 3; TNF $\alpha$, tumour necrosis factor alpha.

\section{Ethics Approval and Consent to Participate}

All participants consented to participation and ethics approval for this study was given by Griffith University (MSC/05/HREC).

\section{Consent for Publication}

All participants consented to the publication of results.

\section{Availability of Data and Materials}

The data set during and/or analysed during the current study are available from the corresponding author on reasonable request.

\section{Conflict of Interests}

The authors declare they have no conflict of interests.

\section{Funding}

Gold Coast Health and Medical Research Foundation, Stafford Fox Medical Research Foundation, Mr Douglas Stutt, Alison Hunter Memorial Foundation and Charity for Change for M.E.

\section{Authors' Contributions}

DS and SMG developed the aims and concepts of this project. MF and VG designed the experiments. MF performed the experiments and analysed data. SMG, DS and MF wrote the paper. All authors critically reviewed the paper.

\section{References}

[1] Bansal, A.S., Bradley, A.S., Bishop, K.N., Kiani-Alikhan, S. and Ford, B. (2012) Chronic Fatigue Syndrome, the Immune System and Viral Infection. Brain, Behavior, and Immunity, 26, 24-31. https://doi.org/10.1016/j.bbi.2011.06.016

[2] Carruthers, B.M., van de Sande, M.I., De Meirleir, K.L., Klimas, N.G., Broderick, G., Mitchell, T., Staines, D., Powles, A.C., Speight, N., Vallings, R., et al. (2011) Myalgic Encephalomyelitis: International Consensus Criteria. Journal of Internal Medicine, 270, 327-338. https://doi.org/10.1111/j.1365-2796.2011.02428.x

[3] Johnston, S., Brenu, E.W., Staines, D. and Marshall-Gradisnik, S. (2013) The Prevalence of Chronic Fatigue Syndrome/Myalgic Encephalomyelitis: A Meta-Analysis. Clinical Epidemiology, 5, 105-110. https://doi.org/10.2147/CLEP.S39876

[4] Aaron, L.A., Burke, M.M. and Buchwald, D. (2000) Overlapping Conditions among Patients with Chronic Fatigue Syndrome, Fibromyalgia, and Temporomandibular Disorder. Archives of Internal Medicine, 160, 221-227. https://doi.org/10.1001/archinte.160.2.221

[5] Lembo, T.J. and Fink, R.N. (2002) Clinical Assessment of Irritable Bowel Syndrome. 
Journal of Clinical Gastroenterology, 35, S31-S36. https://doi.org/10.1097/00004836-200207001-00007

[6] Barbara, G., De Giorgio, R., Stanghellini, V., Cremon, C., Salvioli, B. and Corinaldesi, R. (2004) New Pathophysiological Mechanisms in Irritable Bowel Syndrome. Alimentary Pharmacology \& Therapeutics, 20, 1-9. https://doi.org/10.1111/j.1365-2036.2004.02036.x

[7] Johnston, S.C., Staines, D.R. and Marshall-Gradisnik, S.M. (2016) Epidemiological Characteristics of Chronic Fatigue Syndrome/Myalgic Encephalomyelitis in Australian Patients. Clinical Epidemiology, 8, 97-107.

https://doi.org/10.2147/CLEP.S96797

[8] Fremont, M., Coomans, D., Massart, S. and De Meirleir, K. (2013) High-Throughput 16S rRNA Gene Sequencing Reveals Alterations of Intestinal Microbiota in Myalgic Encephalomyelitis/Chronic Fatigue Syndrome Patients. Anaerobe, 22, 50-56. https://doi.org/10.1016/j.anaerobe.2013.06.002

[9] Frank, D.N., Robertson, C.E., Hamm, C.M., Kpadeh, Z., Zhang, T., Chen, H., Zhu, W., Sartor, R.B., Boedeker, E.C., Harpaz, N., et al. (2011) Disease Phenotype and Genotype Are Associated with Shifts in Intestinal-Associated Microbiota in Inflammatory Bowel Diseases. Inflammatory Bowel Diseases, 17, 179-184. https://doi.org/10.1002/ibd.21339

[10] Giloteaux, L., Goodrich, J.K., Walters, W.A., Levine, S.M., Ley, R.E. and Hanson, M.R. (2016) Reduced Diversity and Altered Composition of the Gut Microbiome in Individuals with Myalgic Encephalomyelitis/Chronic Fatigue Syndrome. Microbiome, 4, 30. https://doi.org/10.1186/s40168-016-0171-4

[11] ter Wolbeek, M., van Doornen, L.J., Kavelaars, A., van de Putte, E.M., Schedlowski, M. and Heijnen, C.J. (2007) Longitudinal Analysis of Pro- and Anti-Inflammatory Cytokine Production in Severely Fatigued Adolescents. Brain, Behavior, and Immunity, 21, 1063-1074. https://doi.org/10.1016/j.bbi.2007.04.007

[12] Skowera, A., Cleare, A., Blair, D., Bevis, L., Wessely, S.C. and Peakman, M. (2004) High Levels of Type 2 Cytokine-Producing Cells in Chronic Fatigue Syndrome. Clinical \& Experimental Immunology, 135, 294-302. https://doi.org/10.1111/j.1365-2249.2004.02354.x

[13] Brenu, E.W., van Driel, M.L., Staines, D.R., Ashton, K.J., Ramos, S.B., Keane, J., Klimas, N.G. and Marshall-Gradisnik, S.M. (2011) Immunological Abnormalities as Potential Biomarkers in Chronic Fatigue Syndrome/Myalgic Encephalomyelitis. Journal of Translational Medicine, 9, 81. https://doi.org/10.1186/1479-5876-9-81

[14] Chia, J.K. and Chia, A.Y. (2008) Chronic Fatigue Syndrome Is Associated with Chronic Enterovirus Infection of the Stomach. Journal of Clinical Pathology, 61, 43-48. https://doi.org/10.1136/jcp.2007.050054

[15] Kavelaars, A., Kuis, W., Knook, L., Sinnema, G. and Heijnen, C.J. (2000) Disturbed Neuroendocrine-Immune Interactions in Chronic Fatigue Syndrome. The Journal of Clinical Endocrinology \& Metabolism, 85, 692-696.

[16] Raison, C.L., Lin, J.M. and Reeves, W.C. (2009) Association of Peripheral Inflammatory Markers with Chronic Fatigue in a Population-Based Sample. Brain, Behavior, and Immunity, 23, 327-337. https://doi.org/10.1016/j.bbi.2008.11.005

[17] Fletcher, M.A., Zeng, X.R., Barnes, Z., Levis, S. and Klimas, N.G. (2009) Plasma Cytokines in Women with Chronic Fatigue Syndrome. Journal of Translational Medicine, 7, 96. https://doi.org/10.1186/1479-5876-7-96

[18] Broderick, G., Fuite, J., Kreitz, A., Vernon, S.D., Klimas, N. and Fletcher, M.A. (2010) A Formal Analysis of Cytokine Networks in Chronic Fatigue Syndrome. 
Brain, Behavior, and Immunity, 24, 1209-1217.

https://doi.org/10.1016/j.bbi.2010.04.012

[19] Clarke, G., Quigley, E.M., Cryan, J.F. and Dinan, T.G. (2009) Irritable Bowel Syndrome: Towards Biomarker Identification. Trends in Molecular Medicine, 15, 478-489. https://doi.org/10.1016/j.molmed.2009.08.001

[20] Lee, K.J. and Tack, J. (2010) Altered Intestinal Microbiota in Irritable Bowel Syndrome. Neurogastroenterology \& Motility, 22, 493-498. https://doi.org/10.1111/j.1365-2982.2010.01482.x

[21] Maes, M., Mihaylova, I. and Leunis, J.C. (2007) Increased Serum IgM Antibodies Directed against Phosphatidyl Inositol (Pi) in Chronic Fatigue Syndrome (CFS) and Major Depression: Evidence That an IgM-Mediated Immune Response against Pi Is One Factor Underpinning the Comorbidity between both CFS and Depression. Neuro Endocrinology Letters, 28, 861-867.

[22] Maes, M., Mihaylova, I. and Leunis, J.C. (2006) Chronic Fatigue Syndrome Is Accompanied by an IgM-Related Immune Response Directed against Neopitopes Formed by Oxidative or Nitrosative Damage to Lipids and Proteins. Neuro Endocrinology Letters, 27, 615-621.

[23] Nilius, B. and Szallasi, A. (2014) Transient Receptor Potential Channels as Drug Targets: From the Science of Basic Research to the Art of Medicine. Pharmacological Reviews, 66, 676-814. https://doi.org/10.1124/pr.113.008268

[24] Clapham, D.E. (2003) TRP Channels as Cellular Sensors. Nature, 426, 517-524. https://doi.org/10.1038/nature02196

[25] Oberwinkler, J. and Philipp, S.E. (2007) TRPM3. Handbook of Experimental Pharmacology, 222, 427-459. https://doi.org/10.1007/978-3-642-54215-2_17

[26] Marshall-Gradisnik, S., Huth, T., Chacko, A., Johnston, S., Smith, P. and Staines, D. (2016) Natural Killer Cells and Single Nucleotide Polymorphisms of Specific Ion Channels and Receptor Genes in Myalgic Encephalomyelitis/Chronic Fatigue Syndrome. The Application of Clinical Genetics, 9, 39-47.

https://doi.org/10.2147/TACG.S99405

[27] Nguyen, T., Staines, D., Nilius, B., Smith, P. and Marshall-Gradisnik, S. (2016) Novel Identification and Characterisation of Transient Receptor Potential Melastatin 3 Ion Channels on Natural Killer Cells and B Lymphocytes: Effects on Cell Signalling in Chronic Fatigue Syndrome/Myalgic Encephalomyelitis Patients. Biological Research, 49, 27. https://doi.org/10.1186/s40659-016-0087-2

[28] Nguyen, T., Johnston, S., Chacko, A., Gibson, D., Cepon, J., Smith, P., Staines, D. and Marshall-Gradisnik, S. (2016) Novel Characterisation of Mast Cell Phenotypes from Peripheral Blood Mononuclear Cells in Chronic Fatigue Syndrome/Myalgic Encephalomyelitis Patients. Asian Pacific Journal of Allergy and Immunology, 35, 75-81.

[29] Phelan, K.D., Shwe, U.T., Abramowitz, J., Wu, H., Rhee, S.W., Howell, M.D., Gottschall, P.E., Freichel, M., Flockerzi, V., Birnbaumer, L. and Zheng, F. (2013) Canonical Transient Receptor Channel 5 (TRPC5) and TRPC1/4 Contribute to Seizure and Excitotoxicity by Distinct Cellular Mechanisms. Molecular Pharmacology, 83, 429-438. https://doi.org/10.1124/mol.112.082271

[30] Marshall-Gradisnik, S., Smith, P., Nilius, B. and Staines, D.R. (2015) Examination of Single Nucleotide Polymorphisms in Acetylcholine Receptors in Chronic Fatigue Syndrome Patients. Immunology and Immunogenetics Insights, 7, 7-20. https://doi.org/10.4137/III.S25105

[31] Fukuda, K., Straus, S.E. Hickie, I., Sharpe, M.C., Dobbins, J.G. and Komaroff, A. 
(1994) The Chronic Fatigue Syndrome: A Comprehensive Approach to Its Definition and Study. International Chronic Fatigue Syndrome Study Group. Annals of Internal Medicine, 121, 953-959. https://doi.org/10.7326/0003-4819-121-12-199412150-00009

[32] Hu, F.B. (2002) Dietary Pattern Analysis: A New Direction in Nutritional Epidemiology. Current Opinion in Lipidology, 13, 3-9. https://doi.org/10.1097/00041433-200202000-00002

[33] Brenu, E.W., Ashton, K.J., Batovska, J., Staines, D.R. and Marshall-Gradisnik, S.M. (2014) High-Throughput Sequencing of Plasma microRNA in Chronic Fatigue Syndrome/Myalgic Encephalomyelitis. PLoS ONE, 9, e102783. https://doi.org/10.1371/journal.pone.0102783

[34] Hardcastle, S.L., Brenu, E.W., Johnston, S., Nguyen, T., Huth, T., Ramos, S., Staines, D. and Marshall-Gradisnik, S. (2015) Longitudinal Analysis of Immune Abnormalities in Varying Severities of Chronic Fatigue Syndrome/Myalgic Encephalomyelitis Patients. Journal of Translational Medicine, 13, 299. https://doi.org/10.1186/s12967-015-0653-3

[35] Fruhwald, J., Camacho Londono, J., Dembla, S., Mannebach, S., Lis, A., Drews, A., Wissenbach, U., Oberwinkler, J. and Philipp, S.E. (2012) Alternative Splicing of a Protein Domain Indispensable for Function of Transient Receptor Potential Melastatin 3 (TRPM3) Ion Channels. The Journal of Biological Chemistry, 287, 36663-36672. https://doi.org/10.1074/jbc.M112.396663

[36] Komaroff, A.L. and Buchwald, D. (1991) Symptoms and Signs of Chronic Fatigue Syndrome. Reviews of Infectious Diseases, 13, S8-S11. https://doi.org/10.1093/clinids/13.Supplement_1.S8

[37] Camus, F., Henzel, D., Janowski, M., Raguin, G., Leport, C. and Vildé, J. (1992) Unexplained Fever and Chronic Fatigue: Abnormal Circadian Temperature Pattern. The European Journal of Medicine, 1, 30-36.

[38] Holzer, P. (2011) TRP Channels in the Digestive System. Current Pharmaceutical Biotechnology, 12, 24-34. https://doi.org/10.2174/138920111793937862

[39] Holzer, P. (2007) Role of Visceral Afferent Neurons in Mucosal Inflammation and Defense. Current Opinion in Pharmacology, 7, 563-569. https://doi.org/10.1016/j.coph.2007.09.004

[40] Light, A.R., Bateman, L., Jo, D., Hughen, R.W., Vanhaitsma, T.A., White, A.T. and Light, K.C. (2012) Gene Expression Alterations at Baseline and Following Moderate Exercise in Patients with Chronic Fatigue Syndrome and Fibromyalgia Syndrome. Journal of Internal Medicine, 271, 64-81. https://doi.org/10.1111/j.1365-2796.2011.02405.x

[41] Akbar, A., Yiangou, Y., Facer, P., Brydon, W.G., Walters, J.R., Anand, P. and Ghosh, S. (2010) Expression of the TRPV1 Receptor Differs in Quiescent Inflammatory Bowel Disease with or without Abdominal Pain. Gut, 59, 767-774.

https://doi.org/10.1136/gut.2009.194449

[42] Cenac, N., Bautzova, T., Le Faouder, P., Veldhuis, N.A., Poole, D.P., Rolland, C., Bertrand, J., Liedtke, W., Dubourdeau, M., Bertrand-Michel, J., et al. (2015) Quantification and Potential Functions of Endogenous Agonists of Transient Receptor Potential Channels in Patients with Irritable Bowel Syndrome. Gastroenterology, 149, 433-444.e437. https://doi.org/10.1053/j.gastro.2015.04.011

[43] Barbara, G., Stanghellini, V., De Giorgio, R., Cremon, C., Cottrell, G.S., Santini, D., Pasquinelli, G., Morselli-Labate, A.M., Grady, E.F., Bunnett, N.W., et al. (2004) Activated Mast Cells in Proximity to Colonic Nerves Correlate with Abdominal Pain 
in Irritable Bowel Syndrome. Gastroenterology, 126, 693-702. https://doi.org/10.1053/j.gastro.2003.11.055

[44] D’Aldebert, E., Cenac, N., Rousset, P., Martin, L., Rolland, C., Chapman, K., Selves, J., Alric, L., Vinel, J. and Vergnolle, N. (2011) Transient Receptor Potential Vanilloid 4 Activated Inflammatory Signals by Intestinal Epithelial Cells and Colitis in Mice. Gastroenterology, 140, 275-285. https://doi.org/10.1053/j.gastro.2010.09.045

[45] Ruggieri, M.R. and Braverman, A.S. (2013) Gastric Body Cholinergic Contractile Signal Transduction in M2 and M3 Receptor Knockout Mice. Journal of Receptor and Signal Transduction Research, 33, 249-254. https://doi.org/10.3109/10799893.2013.802803

[46] Toth, B.I., Konrad, M., Ghosh, D., Mohr, F., Halaszovich, C.R., Leitner, M.G., Vriens, J., Oberwinkler, J. and Voets, T. (2015) Regulation of the Transient Receptor Potential Channel TRPM3 by Phosphoinositides. The Journal of General Physiology, 146, 51-63. https://doi.org/10.1085/jgp.201411339

[47] Badheka, D., Borbiro, I. and Rohacs, T. (2015) Transient Receptor Potential Melastatin 3 Is a Phosphoinositide-Dependent Ion Channel. The Journal of General Physiology, 146, 65-77. https://doi.org/10.1085/jgp.201411336

[48] Brenu, E.W., van Driel, M.L., Staines, D.R., Ashton, K.J., Hardcastle, S.L., Keane, J., Tajouri, L., Peterson, D., Ramos, S.B. and Marshall-Gradisnik, S.M. (2012) Longitudinal Investigation of Natural Killer Cells and Cytokines in Chronic Fatigue Syndrome/Myalgic Encephalomyelitis. Journal of Translational Medicine, 10, 88. https://doi.org/10.1186/1479-5876-10-88

[49] Hardcastle, S.L., Brenu, E.W., Johnston, S., Nguyen, Huth, T., Wong, N., Ramos, S., Staines, D. and Marshall-Gradisnik, S. (2015) Characterisation of Cell Functions and Receptors in Chronic Fatigue Syndrome/Myalgic Encephalomyelitis (CFS/ME). BMC Immunology, 16, 35. https://doi.org/10.1186/s12865-015-0101-4

[50] Cooper, M.A., Fehniger, T.A. and Caligiuri, M.A. (2001) The Biology of Human Natural Killer-Cell Subsets. Trends in Immunology, 22, 633-640. https://doi.org/10.1016/S1471-4906(01)02060-9

[51] Bashashati, M., Rezaei, N., Shafieyoun, A., McKernan, D.P., Chang, L., Ohman, L., Quigley, E.M., Schmulson, M., Sharkey, K.A. and Simren, M. (2014) Cytokine Imbalance in Irritable Bowel Syndrome: A Systematic Review and Meta-Analysis. Neurogastroenterology \& Motility, 26, 1036-1048. https://doi.org/10.1111/nmo.12358

[52] Lakhan, S.E. and Kirchgessner, A. (2010) Gut Inflammation in Chronic Fatigue Syndrome. Nutrition \& Metabolism, 7, 79. https://doi.org/10.1186/1743-7075-7-79 